\title{
The Dangers of 'Warming and Replenishing' (wenbu 溫補) during the Ming to Qing Epistemic Transition
}

\author{
Leslie de Vries \\ University of Westminster \\ L.DeVries@westminster.ac.uk
}

\begin{abstract}
Through a case study of Zhao Xianke's 趙獻可 One Principle through Medicine (Yiguan 醫貫) (1617?) and Xu Dachun's 徐大椿 (1693-1771) denouncements of this text, my article zooms in on divergent discourses on the safety and efficacy of medicinal substances and compounds in late imperial China. Although Xu Dachun's fierce attacks on the popular 'warming and replenishing' (wenbu 溫補) therapies can be situated in an epistemic shift from the cosmology of 'Song learning' (songxue 宋學) towards the philology of 'Han learning' ( hanxue 漢學) and 'evidential research' (kaozheng 考證), I argue that more complex issues were at stake as well. Changed political, social, ethical, and economic realities shaped new and multifaceted perceptions of the nature of medicine, the medical profession, and the usage of medicinals in the aftermath of the Ming to Qing transition.
\end{abstract}

\section{Keywords}

China - medical discourse - formulas - cosmology - Han learning - Ming-Qing transition

In 1741, the eminent physician Xu Dachun 徐大椿 (1693-1771) completed Yiguan bian 醫貫砭 (Critique on Yiguan), a commentated anthology of Zhao Xianke's 趙獻可 (sixteenth to seventeenth century) work entitled Yiguan 
(One Principle through Medicine, 1617?). ${ }^{1}$ The choice for the term bian ('critique') does not leave much to the imagination. The etymology of this word goes back to a sharp stone medical implement. In Xu's time, bian referred to metal lancets used to remove purulent ulcers. ${ }^{2} \mathrm{Xu}$ Dachun clearly sought to eradicate the 'warming and replenishing' (wenbu) medicine propagated in Yiguan. ${ }^{3}$ His arrows were not aimed at Zhao Xianke alone. Xu Dachun deemed the seventeenth-century scholar-cum-physician Lü Liuliang 呂留良 (1629-83) responsible for popularising Zhao Xianke's style of medicine:

Zhao Yangkui [Xianke]'s Yiguan became popular. This was not something that could be achieved by the power of Mr Zhao alone. Mr Lü Wanchun [Liuliang] enjoyed temporarily great reputation. Those who trusted his scholarship at this time also trusted his medicine. If he considered something to be true, who would have dared to say that he was wrong?4

According to $\mathrm{Xu}$, Lü abused his literati status to propagate a simplistic style of medicine that promised to cure all possible illnesses:

Only by remembering a number of formulas, he transmitted a lost learning. Being an art that is extremely elevated, but extremely easy to achieve; with effects that come extremely fast, and having an extremely good reputation, how should it not become popular throughout the world? Yet, what if it is a technique of killing people that is not put to an end! Alas! The harm of a criminal can be stopped, but the harm of an admired criminal cannot be stopped. ${ }^{5}$

The best Xu Dachun could do was to show his readers how the medicine of Yiguan derailed from the classics. Xu's fierce criticism of Zhao Xianke is

1 Yiguan bian is one of the seven medical texts written by Xu Dachun, and published during his lifetime, see Unschuld 1998, p. 43. In Yiguan bian, the contents of the six juan are reduced to two juan, containing a selection of passages in the order as they appear in Zhao Xianke's text.

2 For the specific meaning of bian in external medicine see, for instance, the chapter 'Yongju bianfa ge' 癰疽砭法歌 ('Song on the Bian Method [for Treating] Ulcers') in Yizong jinjian, j. 61, p. 6ob. Compare with HYDCD 7, p. 1015.

3 Although other styles of medicine, and 'Warm disease' (wenbing 溫病) in particular, became important during the Qing, wenbu remained popular (Jiang Zhushan 2007). On the development of wenbing, see Hanson 2011.

4 Yiguan bian $(x u)$, p. 107. The master text for most modern reprints of Yiguan is Lü Liuliang's Tiangai Lou 天蓋樓 edition of the Kangxi era (1662-1722), see Chen Yongping 1995, pp. 3-5.

5 Yiguan bian $(x u)$, p. 107. 
illustrative for his own approach to medicine and can be placed in a broader epistemic shift among late Ming to early Qing literati in Jiangnan (江南) China, an area called 'South of the Yangtze River'. This shift was characterised by developing from the philosophy grounded in 'Song learning' (songxue 宋學) to the philology of 'Han learning' (hanxue 漢學) and 'evidential research' (kaozheng 考證), as Benjamin Elman coined it. ${ }^{6}$ In my case study of Xu Dachun's criticism of 'warming and replenishing' (wenbu) medicine, I first frame Zhao Xianke's and Xu Dachun's diverging perceptions on safe and effective medical treatment - materialised in their discussions on specific formulas and medicinal substances - within their respective epistemic stances. Although polemics are not uncommon in Chinese medical literature, and discussions on warming versus attacking therapies predate late imperial times, Xu Dachun's attacks on Zhao Xianke's 'warming and replenishing' style of medicine were extremely hostile. In the final section of this article, I relate Xu's ideas on medical safety and efficacy to changed political, social, cosmological, and ethical realities in the aftermath of the Ming to Qing transition. ${ }^{7}$ By doing so, the opposition between Zhao's and Xu's epistemic stances reveals a slightly different outlook, which appears to be more complex than we would expect at first glance.

\section{Zhao Xianke's Medical Principles: Warming and Replenishing the 'Gate of Life'}

In the opening section of his work Yiguan, Zhao Xianke makes a radical claim: 'The human body still has another ruler, which is not the heart.' ${ }^{8}$ According to Zhao, the 'heart' (xin 心), a material structure in the chest, occupies the same hierarchical level as all other internal organs of the body. The actual genuine ruler, however, was something formless and related to a reality preceding the existence of forms. Following various leads, Zhao Xianke locates this formless ruler of the body above the seventh vertebra, right in between the two kidneys, on a location which in the acumoxa literature is known as the 'gate of life' (mingmen 命門). Moreover, this ruler functions through its two formless aspects: 'minister fire' (xianghuo 相火) and 'genuine water' (zhenshui 真水),

6 On the emergence of Han learning and evidential research, see Elman 1984. For Han criticism on Song learning in medicine, and the role of Xu Dachun in particular, see Elman 2005, pp. 232-6.

7 Xu Dachun warned against unsafe medicinals that 'harm' ( $h a i$ 害) or even 'kill' (sha 殺) the patient. The term he most commonly used to denote 'efficacy' is youxiao 有效.

8 Yiguan, j. 1, p. 2 a. 
which Zhao Xianke describes and depicts as two small apertures on the left and on the right of the gate of life. Throughout Yiguan, Zhao explains how two formulas, the 'Pill with Six Ingredients' (Liuwei wan 六味丸) and the 'Pill with Eight Ingredients' (Bawei wan 八味丸) balance 'genuine water' and 'minister fire', and hence how they treat dysfunctions of the formless ruler. ${ }^{9}$

Although no one had ever before placed the 'gate of life' on a higher hierarchical position than the heart, Zhao Xianke was not the first to point out its preeminence in the body. Whereas the Inner Classic of the Yellow Emperor (Huangdi neijing 黃帝內經) referred to the 'gate of life' in the context of the eyes, in the Classic of Difficult Issues (Nanjing 難經) it is identified as the right kidney. In this last meaning especially, the term rose into prominence from the Song dynasty onwards, when 'minister fire' (the physiological fire of the kidneys) referred to the right kidney, or the 'gate of life'.10 Ever since, doctors disputed its exact location and function. ${ }^{11}$ Late Ming dynasty physicians especially associated with the so-called wenbu xuepai ('warming and replenishing current')—including Sun Yikui 孫一奎 (c. 1522-1619), Zhang Jiebin 張介賓 (1563-1640), and Zhao Xianke - made the 'gate of life' central to their medical discourse. Although these doctors all regarded the 'gate of life' as the bodily equivalent of the cosmological primal yang contained between the two yin of the trigram 'water' (kan 坎, 亖), and referred to other vocabulary borrowed from the Classic of Changes (Yijing 易經), their explanations went far beyond orthodox Neo-Confucian speculations. In their elaborations on the 'gate of life' as the 'pre-heavenly supreme ultimate' (xiantian taiji 先天太極) in the body, they also referred to Buddhism and, even more extensively, to Daoist internal alchemy. ${ }^{12}$ As such, the texts of these medical authors strongly reflect a 'unity between the Three Teachings' (sanjiao he yi 三教合一), which was popular among the scholarly elite of the time.

For their therapeutics, these late Ming dynasty physicians all followed Xue Ji's 薛己 (1487-1559) ideas on replenishing. Xue, who is recognised as the father of wenbu medicine, synthesised earlier strategies voiced by the

9 These two Pills are multi-component compounds formed by mixing the ingredients (see below) with refined honey. They have the size of Wutong tree seeds.

10 The fire of the heart was called 'governor fire' (junhuo 君火). For the emergence of two fires in the context of Song dynasty medical theory, see Despeux 2001.

11 Most physicians identified the 'gate of life' as a material structure in the body: one of the kidneys, both kidneys, the grease in the kidneys, the womb, etc. For Zhao Xianke, in contrast, the 'gate of life' was formless. For an elaborate account of the locations and functions of the 'gate of life' in medical history, see Chang Chia-feng 1998. For a discussion on Zhang Jiebin's identification of the 'gate of life' as womb, see Wu 2010. 
famous Jin-Yuan masters Li Gao 李杲 (1180-1251) and Zhu Zhenheng 朱震亨 (1282-1358). If depletion was due to a failure of yangqi in the central regions of the trunk, Xue Ji applied Li Gao's therapeutics of replenishing the spleenstomach. Xue also took Zhu Zhenheng's emphasis on yin depletion as cause of disease into account. Yet he departed from Zhu's therapies, which had become paramount during the Ming dynasty. ${ }^{13}$ Instead of applying Zhu's formulas with cold and bitter ingredients, Xue promoted the (above mentioned) Pill with Eight Ingredients and the Pill with Six Ingredients to warm and replenish water and fire of the kidneys. Xue Ji's late Ming dynasty followers cosmologically framed this approach by elaborating on the physiological importance of the 'gate of life' in the body.

Zhao Xianke was rigidly conservative in his adherence to Xue Ji's therapies. In his opinion, Xue, and a handful of other physicians, had understood the true meaning of Zhang Ji's ancient compositions from the Han dynasty. According to Zhao, the formula of the Pill with Eight Ingredients, or Kidney Qi Pill (Shenqi wan 腎氣丸) as it is called in Zhang Ji's Essential Strategies in a Golden Casket (Jingui yaolüe 金貴要略), in particular embodied profound cosmological understandings. Hence, Zhao points out: 'Contemporary people are not as good as the ancients. Therefore, I do not venture to compose a formula myself'. ${ }^{4}$ However, in his explanations of medical formulas, Zhao went much further than other wenbu physicians. By means of the so-called 'post-heavenly diagrammatic ordering of trigrams' (houtian bagua tu 後天八 卦圖), Zhao explains how a handful of formulas could affect the functioning of the 'pre-heavenly' qi (xiantian 先天, or the formless qi of the 'gate of life') in the body. As such, Zhao Xianke claims that he revealed Zhang Ji's 'mysterious secret, kept for more than two-thousand [ sic] years. ${ }^{15}$

In the version by Xue Ji and Zhao Xianke, the Pill with Eight Ingredients contains the following ingredients, followed by dosage:

cooked rehmannia root (shu dihuang 熟地黄, eight liang)

chinese yam (shanyao 山藥, four liang)

cornus fruit (shanzhuyu rou 山茱莫肉, four liang)

moutan root bark (danpi 丹皮, three liang)

white poria (baifuling 白获苓, three liang)

water plantain (zexie 澤瀉, three liang)

13 For an elaborate discussion on Zhu Zhenheng's influence during the Ming dynasty, see Zhang Xueqian 2012.

14 Yiguan, j. 6, p. 17 a.

15 Yiguan, j. 3, p. 14a. 
cinnamon bark (rougui 肉桂, one liang)

and, aconite root (fuzi 附子, one liang $)^{16}$

The Pill with Six Ingredients, designed by the Song dynasty paediatrician Qian Yi 錢乙 (c. 1032-1113), is a variation of the Pill with Eight Ingredients. The Pill with Six Ingredients does not contain cinnamon bark and aconite root, but is otherwise identical to the Pill with Eight Ingredients. According to Zhao Xianke, these pills balance 'genuine water' and 'minister fire' without depleting them. Zhao praises moistening qualities of the ingredients of the Pill with Six Ingredients, which foster 'genuine water'. This water differs from water with form. Zhao Xianke metaphorically describes it as the oil of a lamp, which 'minister fire' needs in order to burn. If 'genuine water' is heavily depleted, formless fire has nothing to which it can attach itself. It flares up, and causes damage in the upper regions of the body. The two extra ingredients of the Pill with Eight Ingredients, cinnamon bark and aconite root, have the ability to guide flaring 'minister fire' (compared to 'dragon and thunder fire') back to the ocean in the water regions of the body. Zhao starts his explanation of the Pill with Eight Ingredients by referring to the trigram kan:

The 'gentleman' (junzi 君子) perceives it symbolically in kan, and knows that the 'way of water and fire' (shui huo zhi dao 水火之道) is contained inside the kidneys. Well, one yang resides in two yin and forms kan. ${ }^{17}$

This yin has to be fostered, and should not be harmed by excessive sexual behaviour, for instance. Neither should cold and bitter ingredients be used. Cold and bitter only supplement yin on a superficial level, but, worse, damage the $y$ ang fire contained inside $y$ in.

The symptomatic appearance of 'heat' ( fa re 發熱) is a major preoccupation throughout Yiguan. ${ }^{18}$ Zhao Xianke particularly regrets the popular but irresponsible use of the Cold Damage formulas Ephedra Decoction (Mahuang tang 麻黃湯) and Cinnamon Twig Decoction (Guizhi tang 桂枝湯) for treating

16 Yiguan, j.4, pp. 1a-b. Xu Dachun points out that in ancient times instead of cooked rehmannia root, only 'dried' (gan 乾) or 'fresh' (sheng 生) rehmannia root were used Yiguan bian, p. 134.

17 Yiguan, j. 4, p. 10a.

18 'Fa re' is often translated as 'fever'. Yet, being 'abnormal bodily heat that can be detected by palpitation or that is experienced subjectively', it has a broader semantic scope than the English word 'fever', see Wiseman and Feng 1998, p. 278. 
symptomatic heat. ${ }^{19}$ For Zhao Xianke, effective medical treatment starts with a correct diagnosis, on which basis appropriate therapeutics should be chosen. This requires a broad range of knowledge about the various causes of heat. Providing a wrong therapy can be disastrous:

If you read the books on Cold Damage, but not the books of Dongyuan [Li Gao], you will not understand 'internal damage' and murder will be manifold. If you read the books of Dongyuan, but not the books of Danxi [Zhu Zhenheng], you will not understand 'yin deficiency', and murder will be manifold. If you read the books of Danxi, but not the books of Mr Xue [Ji], you will not understand 'genuine yin and genuine $y a n g$ ', and murder will equally be manifold. ${ }^{20}$

In other words, Zhu Zhenheng contributed by pointing out the importance of supplementing yin. Yet, in the eyes of Zhao Xianke, Zhu failed to understand $y$ in at a most fundamental level, where both formless fire (genuine yang or 'minister fire') and formless water (genuine yin or 'genuine water'), the roots of yin and yang, interact. ${ }^{21}$ As I have shown, based on this epistemic fallacy, Zhao argued that Zhu's therapies jeopardised the creative force of formless fire in the body, and caused many untimely deaths. ${ }^{22}$

Although Zhao Xianke did not exclude a temporary use of expelling ingredients, he supports his general approach of replenishing by quoting a phrase from the 33rd chapter of the Suwen 素問 (Basic Questions, hereafter sw 33) which is part of the Huangdineijing: 'Where evil gathers, qi must be depleted'. ${ }^{23}$ Zhao further refers to Sunzi's military strategies and Mengzi's ethics for criticising aggressive medical strategies, and these include the strategies of Zhu Zhenheng, the Neo-Confucian doctor par excellence:

Only take replenishing the upright $[q i]$ as the main strategy. You may not attack askew $[q i]$. When upright $q i$ gathers in strength, it spontaneously

19 Referring to these formulas, Zhao Xianke further states: 'Nowadays, physicians often advertise: "Treating Cold Damage during the four seasons." If the names are not correct, speech is inconsistent' (ming bu zheng ze yan bu shun 名不正則言不順), Yiguan, j. 2, p. 25a. This sentence is a quote from the Analects of Confucius (Lunyuj.13, p. 1a), and is the locus classicus for his famous 'rectification of names' (zhengming 正名).

20 Yiguan, j. 2, p. 32a.

21 For a more extensive explanation of causes of heat and various treatment strategies, see Yiguan, j. 4, pp. 14b-15b.

22 de Vries 2012, p. 249.

23 sw 33, j. 9, p. 15b. Cf. Yiguan, j. 2, p. 3a. 
pushes cold evil out. After sweating, there will be recovery. The word 'attacking' is something a 'humane person' (renren 仁人) detests. Achieving a hundred victories in a hundred wars is being proficient in warfare. 'Subduing the soldiers of the enemy without war is being proficient in goodness'. Hence, it is said: 'The one who is proficient in war receives the capital punishment.'. ${ }^{24}$

Here, upright $q i$ can refer to both the post-heavenly qi of the spleen-stomach and the pre-heavenly $q i$ of the 'gate of life' in the kidneys region. If post-heavenly $q i$ is depleted, formulas such as Li Gao's Supplementing the Centre and Increasing Q $i$ Decoction (Buzhong yiqi tang 補中益氣湯) would be appropriate to take. Yet Zhao laments that Li Gao did not reach the realm of formless, pre-heavenly $q i$ located in the kidneys region - the origin of life and everything which exists in the body, including the $q i$ that drives the processes in the spleen-stomach. Thus, according to Zhao Xianke, at a most fundamental level, the Pill with Six Ingredients and the Pill with Eight Ingredients proved their efficacy. ${ }^{25}$

Not everyone was convinced about the safety and efficacy of some of the ingredients of the two pills. Chen Jiamo 陳嘉謨 (1486-1570), for instance, proposed to fry rehmannia root with ginger juice. Otherwise, he argued, rehmannia root would stick to the diaphragm, and cause phlegm. Zhao Xianke counters this criticism by pointing out that the process of frying with ginger juice would alter the moistening properties of rehmannia root. The pills should be taken on an empty stomach and be pushed down with a meal. This ingestion method ascertains the efficacy of the pills by leading them down to the lower regions of the body, and prevents them from lingering in the stomach. ${ }^{26}$ Others pointed to other dangers. Zhang Jiebin, for instance, echoed earlier criticism that poria and water plantain would, instead of replenishing, drain the kidneys too much. Zhang praised Xue Ji for understanding the profound cosmological mechanisms explaining the use of the two pills, but he replaced poria and water plantain in his own variations of the two pills, and pointed out that he 'uses the "idea" ( $y i$ 意) of the Six Ingredients, but not the "formula" (fang 方) of

\footnotetext{
24 Yiguan, j. 2, p. 35b. The first quote is taken from Sunzi ([bingfa], p. 4a); the second one features in Mengzi, Li Lou 1,j. 7, p. 6a. Compare also with Yiguan, j. 6, p. 2b. On Zhu Zhenheng as a Neo-Confucian physician, see Furth 2006.

25 These pills further had a wide range of indications, far beyond the treatment of heat, as discussed in 'Essential Chapters on the Pre-Heavenly' (Xiantian yaolun 先天要論), juan 4 and 5 of Yiguan.

26 Yiguan, j. 4, pp. 19b-2oa.
} 
the Six Ingredients'. ${ }^{27}$ Zhao Xianke, in contrast, remains faithful to Zhang Ji's classical compositions:

I deeply understood that Zhongjing [Zhang Ji] was the forefather of composing formulas. He clearly considered this formula [the Pill with Eight Ingredients] essential for treating the kidneys. I do not at all dare to alter it according to my 'personal ideas' (siyi 私意). ${ }^{28}$

Hence, Zhao Xianke proposed a fairly straightforward approach to replenishing, backed up with elaborate cosmological explanations. Although his medicine, as described in Yiguan, became popular during the seventeenth century, not much is known about his person or the early history of his text. According to the local history of Yin-county (now part of Ningbo city in Zhejiang province), Zhao was an important physician of this coastal region in the lower reaches of the Yangzi river. He excelled in the study of medicine and the study of the Classic of Changes, he travelled extensively, authored several books, and he had a son who practised medicine as well. ${ }^{29}$ Zhao Xianke's dates of birth and death remain a mystery. Based on a case history recounted in Yiguan, we may assume that he was active in $1617 .{ }^{30}$ Two prefaces to Yiguan, representing two publication traditions, however, link the text to important personae. The first preface is related to the two Xue brothers, the second to Lü Liuliang. ${ }^{31}$

Both Xue Sanxing 薛三省 (1558-1634) and Xue Sancai 薛三才 (1555-1619) were high-ranking Ming officials. Sanxing claimed that his brother, Sancai, the 'Minister of War' (Sima gong 司馬公), was responsible for the first publication of Yiguan. ${ }^{32}$ Sanxing stated, moreover, that Zhao Xianke completed his text in the Yiwulü mountains in the northeastern border region-which would further explain Zhao's nickname, 'Master of Yiwulü' (Yiwulüzi 醫巫闆子). ${ }^{33}$ This

27 Leijing fuyi, j. 3, pp. 22a-23a. Zhang's four variations, Yougui wan 右歸丸 (Left Returning Pill), Zuogui wan 左歸丸 (Right Returning Pill), Yougui yin 右歸飲 (Right Returning Beverage), and Zuogui yin 左歸飲 (Left Returning Beverage), are commonly used in тсм. See, for instance, Deng Zhongjia 2003, pp. 172-3, 180-1.

28 Yiguan, j. 4, pp. 4a-b.

29 Kangxi Yinxian zhi, j. 11b, pp. 26b-27a.

3o Chen Yongping 1995, p. 3.

31 Guo Junshuang 2005, p. 7 .

32 In the Ming and Qing period 'Sima', a title for the minister of war in the Zhou period was used unofficially for executive officials of the Ministry of War. See Hucker 1985, p. $45^{2}$.

de Vries 2012, pp. 47-8. 
was also the region where Sancai lead the Ming defences against Nurhaci's Manchu troops. ${ }^{34}$

Another important name in the publication history of Yiguan is Lü Liuliang. Lü, who had frequented the circles of the foremost Ningbo scholar and antiQing activist Huang Zongxi 黃宗羲 (1610-95), published an annotated edition of Yiguan during the Kangxi period (1662-1722). From Huang's writings we also learn that Yiguan became one of the most influential texts in Ningbo during the second half of the seventeenth century. In a biography on Zhang Jiebin, Huang wrote: 'The popular medical texts of the last twenty years [c. 1650-71] were Zhang Jiebin's Leijing 類經 (Classic in Categories) and Zhao Yangkui's [Xianke's] Yiguan'. ${ }^{55}$ Although Huang continued with a critical remark that 'the knowledge in Yiguan is not thorough', Zhao Xianke and Zhang Jiebin remained medical stars for decades to come, and their fame spread way beyond Ningbo. In his Shenji chuyan 慎疾䇖言 (Humble Opinions on the Careful Treatment of Illnesses) of 1767 , Xu Dachun wrote that the popularity of replenishing therapies was only very recent, and he especially held Zhao Xianke and Zhang Jiebin responsible:

Nowadays, one [doctor] after the other enters the 'way of evil' (modao 魔道). ${ }^{36}$ It started with people like Zhao Yangkui [Xianke] and Zhang Jingyue [Jiebin]. They did not at all know the meaning of composing formulas of the ancient sages. Selfish and self-satisfied, they wrote books and became experts. They also could not know that their abuses would lead to these extremes. I know that 'the heart of Heaven is benevolent' (tianxin ren'ai 天心仁愛). This digression shall not last long! ${ }^{37}$

Notwithstanding Xu Dachun's criticism, texts such as Zhao Xianke's Yiguan and Zhang Jiebin's Leijing remained popular.

\section{Against Replenishing}

Throughout his entire oeuvre, Xu Dachun devoted quite some pages to attacking the therapeutic practice of replenishing medicine. From the outset in Shenji

34 Struve 1998, p. 200.

35 Nanlei wen'an, j. 9, 1a.

36 'Mo' literally means 'demonic'.

37 Shenji chuyan, pp. 552-3. In the first essay of Shenji chuyan (written in 1767), Xu Dachun states that this fashion was not older than three decades, see p. $55^{2}$. 


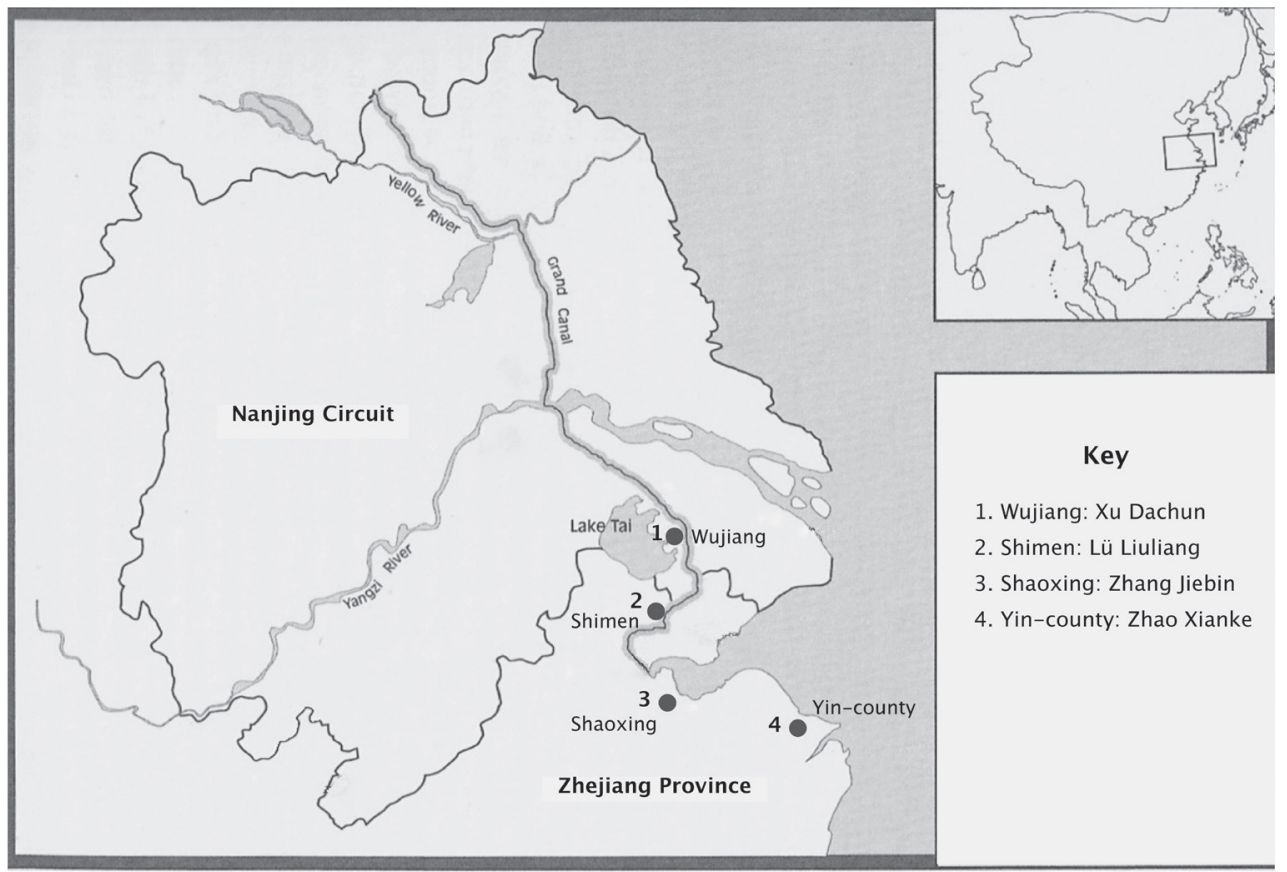

Map of Ming-Qing Jiangnan, indicating places of doctors discussed in the text.

chuyan, for instance, $\mathrm{Xu}$ points out that it is extremely difficult to change the widespread adherence among patients to replenishing medicines. ${ }^{38} \mathrm{Xu}$ laments that people in his days feared dying of depletion and not of a clearly defined illness. Therefore, it was safe for the physician to prescribe replenishing formulas. If death occurred after a replenishing treatment, it was forgiven because the illness (or rather the 'depletion') was incurable, replenishing formulas were given too late, not in the proper dosages, or poor quality ingredients were used. Xu further points out that if death occurred after attacking drugs were prescribed, people blamed the physician's lack of knowledge or the harmful properties of the ingredients that were prescribed. Hence, the expectation of

38 On the 'culture' of replenishment during the Qing, see Jiang Zhushan 2007. Xu Dachun makes a distinction between regions: In Zhejiang, Decoction with Six Ingredients (Liuwei tang 六味湯) and Decoction with Eight Ingredients (Bawei tang 八味湯), and ingredients such as 'ginseng' (renshen 人參) and 'lily turf' (maimendong 麥門冬) were popular; In Jiangnan, this rather concerned Regulating the Centre Decoction (Lizhong tang 理中湯), and ingredients such as aconite, cinnamon bark, prepared 'rehmannia root' (shu dihuang 熟地黃), and 'deer antler' (lurong 鹿茸), see Shenji chuyan, p. 551. 
receiving a replenishing therapy by patients and their families made it hardly possible for the physician to decide on other treatments. ${ }^{39}$

Like Zhao Xianke, Xu Dachun also refers to military metaphor. Yet his strategy of expelling intruding external evil is diametrically opposed to Zhao's idea of supporting upright qi with replenishing drugs. In Yixue yuanliu lun 醫學源 流論 (Essays on the Origins of Medicine, 1775), Xu expounds as follows:

When rebellions occur at any of the four frontiers, an appropriate [defense] is to choose a general and to dispatch troops to quickly drive away [all rebels]. If however, one were to go into the Hall of Learning, to discuss ceremonies and music, then the enemy would [advance quickly] to the gates [of the city]. If therefore [for an illness caused by evil influences that have entered the body from outside] one carelessly employs supplementing [drugs] before the evil influences have been eliminated completely, this will cause evil influences to proceed deeper into [the patient's body, causing him to] die. ${ }^{40}$

$\mathrm{Xu}$ Dachun does not dismiss the phrase of sw 33 ('Where evil gathers, qi must be depleted'), often quoted by wenbu physicians. 'Of course, depleted qi has to be replenished', he says, but 'should the gathered evil not be expelled as well'?41 If a disease is caused by an external intrusion, supplementing therapies with hot drugs, such as aconite and ginseng, may cause violent deaths:

When evil [influences] are present in abundance, and [the physician] gives [the patient] large doses of 'ginseng' ([ren]shen) and 'aconite' (fu[zi]), with the effect that his yang influences come to flourish greatly for some time, while his pathogenic influences are forced to hide away, then, of course, [the patient's] spirit and his [proper] influences are somewhat stabilized. But after one or two days have passed, the [patient's] original influences and evil influences have merged with each other, and [the former] now assist, contrary [to what one might have expected], the latter to develop their poison, with the result of a particularly violent disaster. This is a pattern of a rapidly supplementing [therapy]. ${ }^{42}$

The first chapter of Shenji chuyan is entirely devoted to pointing out the dangers of replenishing formula, see pp. 551-2. See also Zhang Wenping and Qin Yulong 2013, p. 4.

$40 \quad$ Yixue yuanliu lun, p. 195; cf. trans. Unschuld 1998, p. 233.

41 Shenji chuyan, p. 551.

42 Yixue yuanliu lun, p. 184; cf. trans. Unschuld 1998, pp. 172-3, compare also with Yixue yuanliu lun, pp. 191-2; cf. trans. Unschuld 1988, pp. 216-17. In the Shennong bencao jing, the 
However, if the illness is less severe and the patient recovers after replenishing medicines are taken, Xu explains that the 'primary qi' (yuanqi 元氣) of the patient gradually and naturally recovered, unrelated to the medicines used. ${ }^{43}$

Although Xu Dachun in his Shennong bencaojing baizhong lu 神農本草經百 種錄 (Record of One Hundred Kinds from the Divine Farmer's Classic on Materia Medica, 1736) is overall positive about the replenishing properties of ginseng, he warns about the contemporary abuse of the drug: 'Doctors who nowadays use ginseng to save people are few; those who kill people are many. ${ }^{44}$ Again, $\mathrm{Xu}$ points out that the majority of people do not die because of depletion, but because of diseases caused by external evil. Xu further devotes a whole chapter of Yixue yuanliu lun on ginseng, where he defines ginseng as a medicine that 'ruins a person's family and subsequently kill's [that person's] body'. 45 According to $\mathrm{Xu}$ Dachun, the high costs of replenishing drugs, and ginseng in particular, posed a great burden on the patient's family:

[S]tupid people believe that expensive drugs must be good drugs, while cheap drugs are supposed to be inferior, and it is common human nature to love supplementation and to dislike attack. (...). Today prices [for ginseng] have increased tenfold, and the dose [people] consume [in the course of one treatment] is no longer restricted to one or two ch'ien. If [patients from] rich families take two or three liang, this is enough to cause their household to go bankrupt. ${ }^{46}$

$\mathrm{Xu}$ Dachun also considered the preventive use of replenishing drugs to be dangerous, and not only for financial reasons. At birth, Xu explains, a human being obtains the pure qi of heaven and earth. Plants or animals, in contrast, are less pure. Therefore they can be used as medicines to compensate imbalances in

classical text of materia medica, ginseng and aconite are categorised as two very different drugs. Ginseng belongs to the 'upper category' (shangpin 上品), and is a nourishing drug. Aconite, on the other hand, belongs to the 'lower category' (xiapin 下品), and is highly potent and toxic. Also from a modern point of view, aconite is highly toxic. Zhao Xianke was aware that excessive dosages of aconite could cause serious harm to the yin of the lungs, Yiguan, j. 5, p. $32 \mathrm{~b}$. Aconite needed to be prepared carefully before use. On the preparation of aconite see, for instance, Yiguan, j.4, pp. 1b-2a.

43 Shenji chuyan, p. 551.

44 Shennong bencaojing baizhong lu, p. 81.

45 Yixue yuanliu lun, p. 185; cf. trans. Unschuld 1998, p. 179.

46 Ibid., p. 185; cf. trans. Unschuld 1998, pp. 179-80. 
the human body caused by illness. ${ }^{47}$ However, if replenishing drugs are taken without being ill, they become the source of serious imbalances in the human body. Xu especially accuses doctors who promote 'secret formulas' (mifang 秘 方) for prolonging life, that often contain warming and replenishing drugs. He warns that, instead of keeping their promise of a long and healthy life, in many cases ingesting these secret formulas results in an untimely death. ${ }^{48}$

Among his many writings, Xu Dachun devoted one entire work, his above mentioned Yiguan bian, to dismantle the theories and therapeutics of another medical text. In Yiguan bian, Xu selected passages from Zhao Xianke's Yiguan, which he then discussed in his commentaries. He especially tried to convince his readers that Zhao Xianke did not understand the very basics of medicine. One striking example is Zhao's description of Cinnamon Twig Decoction, the first formula listed in Zhang Ji's Shanghan lun 傷寒論 (Treatise on Cold Damage). Xu points out that Zhao forgot to list two essential ingredients, 'fresh ginger' (shengjiang 生葨) and 'jujube' (dazao 大東). ${ }^{49}$ Yet, most of Xu Dachun's attention goes to Zhao Xianke's application of the Pill with Six Ingredients and the Pill with Eight Ingredients. Contrary to Zhao, Xu argues that Zhang Ji never intended the Pill with Eight Ingredients to be a replenishing formula. On the five places where this formula is mentioned in Zhang Ji's Jingui yaolüe, the Pill of Eight Ingredients 'is most of all used to "drain" (xie 㴼) illnesses of cold and dampness in the lower abdomen and the urinary bladder.50

Zhao Xianke's explanation of balancing formless water and formless fire with the ingredients of the Pill with Six Ingredients and the Pill with Eight Ingredients were, in Xu Dachun's eyes, complete nonsense: 'How can six ingredients, which have form, replenish something formless?'51 Xu further highlights incoherencies in Zhao's explanation of the ingredients cinnamon bark and aconite in the Pill with Eight Ingredients. Xu does not understand how these ingredients would replenish while they guide minister fire down to the lower regions:

47 Shennong bencao jing bazhong $l u(x u)$, p. 71. Although Xu Dachun would use replenishing in cases of extreme loss of yinqi (Yixue yuanliu lun, p. 174; cf. trans. Unschuld 1998, pp. 121-2), he points out that patients in ancient times only depended on nutrition, and not on replenishing formulas after recovery from a serious disorder. Replenishing formulas cannot be attested in the classical texts of the Han period, Yixue yuanliu lun, pp. 207-8; cf. trans. Unschuld 1998, pp. 298-9. See also Wu Yunbo 1988, p. $5^{2}$.

48 Shenji chuyan, p. 561.

49 Yiguan bian, p. 123. See also Wu Yunbo 1988, p. 52. The other ingredients of Cinnamon Twig Decoction are 'cinnamon twig' (guizhi 桂枝), peony root, and liquorice root.

5o Yiguan bian, p. 136.

51 Ibid., p. 135 . 
This is replenishing of 'dragon and thunder' [i.e. minister fire], but not extinguishing them. Without paying attention to the coherence in the text, [Zhao Xianke] especially confuses foolish people with big words. ${ }^{52}$

Xu fiercely attacked Zhao's abundant references to cosmology:

The way of the 'eight trigrams' and the 'supreme ultimate' is a 'learning' (xuewen 學問) that reaches through everything, ${ }^{53}$ how would it be suffcient only to remember these two formulas! Is this not [living in] a dream world ${ }^{54}$

Unfortunately, these fancy cosmologies were, in the eyes of Xu Dachun, particularly useful for Zhao Xianke to cheat his literati audience. ${ }^{55}$

\section{Xu Dachun's Alternative and the Limitations of Medicine as a Field of Knowledge}

Here we come to a fundamental difference in epistemic stance. While wenbu doctors tried to treat illness by grasping the cosmological principles through which vitality functions in the body, for Xu Dachun, Zhao Xianke's and Zhang Jiebin's terminology of yin and yang depletion were only 'vague set phrases' ( taoyu 套語). Xu highlights that the ancients clearly 'defined' (ding 定) illnesses by 'names' (bingming 病名). ${ }^{56}$ This started with profound, evidential knowledge of drug properties:

The way of medicine starts with the Bencao [jing] 本草 [經] ([Classic of ] Materia Medica) written by the Divine Farmer. ${ }^{57}$ With one medicinal

$5^{2}$ Ibid., p. 138. Xu Dachun explains the use of these ingredients as follows: 'Water is a cold evil. Hence, medicines such as $f u[z i]$ and [rou gui are used to support yang in order to pass through impediments' (zhu yang tong bi 助陽通痹), see ibid., p. 134.

53 Guanchuan tongtian chedi(貫串通天徹地).

54 Yiguan bian, p. 135 .

55 Shenji chuyan, p. $55^{2}$.

$5^{6}$ As I pointed out in the previous section, Zhao Xianke equally highlighted the importance of 'rectifying the names' (cf. fn. 19).

57 In his Shennong bencao jing baizhong lu, Xu Dachun makes a selection of 100 essential medicines from the original 360 described in the Shennong bencao jing. This stands in stark contrast with later pharmacopoeias which list many more medicines, culminating in Li Shizhen's 李時珍 (1518-93) Bencao gangmu 本草綱目 (Systematic Materia Medica). Xu Dachun emphasises the effectiveness of Shennong's original selection and the limited numbers of medicines used in Zhang Ji's classical formulas. Xu did not completely discard 
substance one illness was treated. Yet, one illness has many 'manifestations' (zheng 證). ${ }^{58}$ Later sages chose medicines that 'match' (dui 對) the manifestations. They combined several ingredients into formulas. Therefore, when treating illnesses, there are first the medicinal substances and then the formulas. ${ }^{59}$

For formulas, Xu Dachun mainly depends on Zhang Ji's classical texts of the Han dynasty. In a majority of cases, Zhang's formulas could be applied without any modification, as in the following case of Cold Damage:

I said: 'These are the manifestations of Great Supporting $Q i$ Decoction (Da chengqi tang 大承氣湯). It should not be “modified” (jiajian 加減). Administer as is [described in] the text.' (...). The divine efficacy (shenxiao 神效) of the ancient formulas is like this. In general, if the ancient formula completely matches the illness and its manifestations, it is not necessary to modify. If the illness is identical, but the manifestations are slightly different, modify according to the manifestations. This principle is very clear, but people cannot apply it. ${ }^{60}$

$\mathrm{Xu}$ acknowledges that not everything is written down in the classics. The constant need for adaptation during treatment requires the active role of a physician with profound knowledge of the classics and experience in practice. Trial and error are part of the process, and this makes medicine difficult to master. ${ }^{61}$

the use of 'new' medicines, discovered partly due to an expansion of the territory, and often useful for treating 'exotic' illnesses. In general, however, he blames a lack of proper knowledge about Shennong's medicines responsible for the amassment of the amount of materia medica in texts from the Tang dynasty onwards, Shennong bencao jing baizhong lu (xu), p. 71; see also Yixue yuanliu lun, pp. 187-8; cf. trans. Unschuld 1998, pp. 193-5.

58 In the comment to this passage zheng 症 is used instead of zheng 證, and defined as 'demarcating' (fenming 分明) 'illnesses' (bing 病). Bing is defined as 'general name' (tong ming 統名), see Shenji chuyan, p. 552. Compare also with Yixue yuanliu lun, pp. 173-4; cf. trans. Unschuld 1998, pp. 115-16. For a general discussion on illness and manifestations ('pathoconditions') in Yixue yuanliu lun, see Unschuld 1998, pp. 11-16. For an elaborate discussion on changes in understandings of zheng from the Song to the present, see Scheid 2014 .

59 Shenji chuyan, p. $55^{2}$.

60 Huixiyian, p. 574 .

61 Shenji chuyan, p. 552. Compare also with Yixue yuanliu lun, p. 199; cf. trans. Unschuld 1998, pp. 254-5. 
Moreover, Xu Dachun explains that the qualities of materia medica have changed over time. Descriptions in ancient texts do not necessarily correspond to the properties that drugs had in his time. Also the places where medicinal substances were gathered differ. For instance, doctors in former times went into the mountains to search for raw ingredients, whereas in recent times they prefer to buy medicinal substances sold in markets. Xu further laments that when they are in short supply, shopkeepers easily cheat them with counterfeits, because doctors are unable to verify the qualities themselves. In most cases, the physician does not come into contact with the drugs they prescribe:

Today's physicians know only how to write standardized prescriptions, and the drugs they [prescribe] are always acquired from shops by the patients themselves. Hence genuine and false [substances] are no longer distinguished, and although a physician may be [as capable as] a spirit, he will not be able to cure a genuine illness with false drugs. ${ }^{62}$

Although Xu Dachun devoted much effort to convince his contemporaries about the necessity of his attacks on replenishing and other problems related to contemporary practices of literari doctors, he was pessimistic about the success of his endeavours. After all, the efficacy of medical treatment is difficult to prove, as Xu Dachun highlights in his foreword to Yiguan bian:

[Among] the 'Lesser Ways' (xiao dao 小道) that people use daily in their lives, 'medicine' ( $y i$ 醫) and 'divination' ( $b u$ 卜) are two opposites. Divination is what is most untrustworthy, [yet] one can be sure of this; medicine is what is most trustworthy, [yet] one can never be sure of it. ${ }^{63}$

In Xu's words, while it is impossible to test the validity and efficacy of divination, in medicine there are some certainties. According to $\mathrm{Xu}$, it is possible 'to decide on the right formula according to the manifestations' (bianzheng dingfang 讋症定方). Properties of the drugs, such as the warming qualities of ginger or the laxative qualities of 'rhubarb' (dahuang 大黃), are clearly observable. Yet, an illness may develop in unpredictable ways:

Sometimes the drugs do not 'strike' (zhong 中) the illness, but, contrarily, there are 'small efficacious effects' (xiao xiao 小效). Sometimes the treatment follows the appropriate method, but does not lead to any result at all. It happens that after there are effects [of the drugs], the illness

\footnotetext{
62 Ibid., pp. 197-8.

63 Yiguan bian $(x u)$, p. 107.
} 
becomes worse. Or, after no effects, the illness disappears gradually. It happens that the drugs are actually [prescribed] without any mistake, but when they strike, the illness becomes more violent. The blame will be on the drugs. Sometimes drugs are completely wrongly [prescribed], but their harm does not show. Mistakenly, the merit is given to these drugs. Patients and their families do not know this, nor do physicians. Therefore, all discussions are diverse and confused. This leads to a deranged provision of medical treatment. Who kills and who keeps alive? There is absolutely no 'settled theory' (yi ding zhi lun 一定之論) [of medicine]. (...) That is why one can never be sure of the way of medicine, and of the 'quality of a physician' (yi zhi liangjian 醫之良賤) even less. ${ }^{64}$

\section{Context and Nuances}

Xu Dachun's fierce criticism of Zhao Xianke's 'warming and replenishing' medicine goes beyond the mere attacks of a Han learning physician on medicine grounded in complex cosmological theories. This becomes clear when we take the political and social aftermath of the Ming to Qing transition into account.

Some of Zhao Xianke's immediate followers might have had strong motivations for practising medicine. Lü Liuliang, for instance, belonged to the Ming loyalist circles of the great scholar Huang Zongxi in East Zhe (Zhedong 浙 東). While Huang embraced Qing rule at a later point in his life, Lü was radicalised in his anti-Manchu sentiments. ${ }^{65}$ Being one of the main representatives of the Cheng-Zhu current, Lü never gave up lecturing and writing about Neo-Confucian orthodoxy. ${ }^{66}$ Practising medicine provided a livelihood in troubled political times. ${ }^{67}$

64 Yiguan bian $(x u)$, p. 107.

65 Lü Liuliang was born into a gentry family in Shimen 石門. Although he took first level examinations in 1653, Lü renounced his official status in 1666, de Bary 2000, p. 18. Lü became a friend of the Huang family in 1641 , who introduced him to the scholar physician Gao Doukui 高斗鬼斗 (1623-70). Through Gao, Lü became acquainted with the medicine of Zhao Xianke. On the relationship between Lü Liuliang and Huang Zongxi, which deteriorated after the death of Gao Doukui in 1670, see Fisher 1984. On the importance of Gao Doukui for transmitting Zhao Xianke's medicine to Lü Liuliang, see Yiguan bian, p. 136.

66 Whereas Lü Liuliang was an adherent of Cheng-Zhu's current of Confucianism, Huang Zongxi was associated with Wang Yangming's current, see Fisher 1984. On germinating Han learning among the Ming loyalist scholars Huang Zongxi and Gu Yanwu, see Elman 2005, pp. 6o, 226.

67 The same counts for Zhao Xianke's immediate follower Gao Doukui. Although Huang Zongxi tried to convince Gao Doukui to spend more time on Confucian learning, Gao 
Lü Liuliang's anti-Qing resentments and scholarship lived on after his death in 1683. His writings inspired Zeng Jing's 曾靜 (1679-1735) failed conspiracy against the Yongzheng (r. 1722-35) emperor in the year $1728 .{ }^{68}$ To set an example, Yongzheng commanded the posthumous punishment of Lü. In 1733, half a century after his death, Lü's corpse was unearthed and dismembered, his descendants also received severe punishments, and his texts, including the commentated edition of Yiguan, were burned and banned. ${ }^{69} \mathrm{Xu}$ Dachun's critique on Zhao Xianke's medicine, as popularised by Lü Liuliang (the 'admired criminal'), was a safe one.

Xu portrays himself as a loyal servant of the Qing. Because health, including that of rulers, depends on medical treatment, a doctor bears a heavy responsibility. Yet Xu complains about the complete lack of respect for the profession. Moreover, because medicine was considered to be 'an inferior occupation', he laments that '[it] will never [be] adopted by an eminent scholar.70 Xu's humble references to medicine as a 'petty profession' or 'Lesser Way' (xiao dao 小 道) stand in stark contrast to the appreciation of the profession in late Ming wenbu texts. Because a physician had to understand and treat the cosmic origin of life, for wenbu authors like Zhao Xianke and Zhang Jiebin, medicine was very similar to the soteriological practices of the three doctrines. ${ }^{71}$ For this reason, Zhang Jiebin became convinced that 'medicine was not a Lesser Way' (yi fei xiao dao ye 醫非小道也), but a 'Great Way' (da dao 大道). ${ }^{72}$ Although $\mathrm{Xu}$ did not exclude epistemic possibilities of gaining wisdom through a state

continued practising medicine, which allowed him not only to support himself but also Huang's scholarly endeavours, see Fisher 1984, pp. 115-17.

68 For a full account, see Fisher 1974. For a historical novel on the subject, see Spence 2001.

69 Goodrich 1943, p. 551.

$70 \quad$ Yixue yuanliu lun (zixu), p. 159; cf. trans. Unschuld 1998, pp. 51-2. Xu was summoned twice to the capital for the treatment of important officials. He died at the capital three days after his second visit, see Unschuld 1998, p. 2. For a translation of Xu's biography by Yuan Mei 袁枚 (1716-98), see ibid., pp. 37-41.

71 See, for instance, Yiguan, j. 1, pp. 10b-11a. Besides Confucianism, wenbu physicians highlighted the importance of Daoist inner alchemical ideals (compare and contrast with Engelfriet 2000). Zhang Jiebin, and also Li Zhongzi, for instance, pointed out that 'the way of medicine connects with the way of alchemy' (yidao tong xiandao 醫道通仙道), whereas Xu Dachun points out that 'the way of medicine connects with the way of government' (yidao tong zhidao 醫道通治道), cf. Leijing, p. 1414 with Nanjing zhiyao, p. 8 and with Yixue yuanliu lun, p. 195. See also de Vries 2014. For Li Zhongzi's preference for Buddhism at the end of his life, see Shanbu yisheng weilun, p. 656. Note also that Lü Liuliang became a Buddhist monk during the last years of his life, be it most certainly for pragmatic reasons, see Goodrich 1943, p. 551 . 
of unity with the cosmos, this rather applied to ancient times: 'When the ancient Sages cured illnesses, they penetrated the facts between heaven and earth, and they sought the origins of life. ${ }^{73}$ But, Xu Dachun also emphasised that sage physicians like Zhang Ji depended largely on what their teachers had acquired before. ${ }^{74}$ Hence, contrary to mystic insights, Xu promoted a humbler and safer approach to medicine. Through a thorough study of the classics, the student of medicine gained a body of knowledge that could be tested through examinations. ${ }^{75}$

Xu Dachun's vision on standardisation, with possibilities for further regulation through certification by the state, fitted the larger Han learning and 'evidential research' (kaozheng 考證) project during the Qing dynasty. ${ }^{76}$ Besides

73 Yixue yuanliu lun, p. 159; cf. trans. Unschuld 1998, p. 51. Xu Dachun did not shun the supernatural. He discussed disorders caused by demons, secret formulas obtained through divinatory means, etc. (cf. Yixue yuanliu lun, pp. 176, 181-2, 191). For Xu Dachun's objections against a medicine based on individual insights, see also Scheid 2014, p. 17. But, also contrast with his appreciation of how Shennong obtained his knowledge of materia medica, Yixue yuanliu lun, p. 189 .

74 Yixue yuanliu lun, p. 219. Xu Dachun highlights the need for acquiring proper medical training from an experienced teacher, cf. Yixue yuanliu lun, p. 223. On scholars who became physicians by book reading only from the Song dynasty onwards, see Leung 2003, pp. 391-2.

75 Yixue yuanliu lun, p. 220. As such, Xu Dachun's emphasis was not on a soteriological ambition of becoming a Confucian Saint (or a Buddha or a Daoist immortal) during one's lifetime, but on applying standardised medical knowledge. This reflects the larger epistemic shift which took place in the period of the Ming to Qing transition: 'In general, the focus on the investigation of things in the early Qing shifted from a pathway to sagehood to a more rigorous methodology for extending all knowledge, whether moral, textual, or worldly', Elman 2005, p. 6o. For a discussion on this shift in the context of changing understandings of zheng 症, and the importance of the concept $y i$ 意 ('consciousness, focus, intention, idea'), see Scheid 2014, pp. 117-24.

$76 \mathrm{Xu}$ is often praised for his tendency towards standardisation of medical practice, see, for instance, Ma Yandong and Sun Zhenghe 1997. One may question how close Xu Dachun's proposals for standardisation based on Han learning philology were to the genuine meaning of Zhang Ji. After 30 years of study, Xu had the 'insight' ( $w u$ 悟) that the original structure of the Shanghan lun was not based on a transmission along the 'conduits' (jing 經), but on 12 main formulas, and attached secondary formulas, for treating well-defined illnesses and their manifestations, Shanghan leifang $(x u)$, p. 227. As Volker Scheid points out, reinterpretations of the Shanghan lun which rejected the importance of the conduits go back to Fang Youzhi 方有执 (1522-99), a late Ming dynasty physician associated with the evidential research movement. A similar approach was followed by Ke Qin 柯 琴 (1662?-1735?). Like Fang, Ke interpreted jing as specific regions (in his case, 'domains of territorial warfare') in the body. He further rearranged the text of the Shanghan lun 
the Han classics (Huangdi neijing, Shennong bencao jing, and Zhang Ji's texts) and a handful of works on paediatrics, women's disorders, and external medicine, Xu Dachun promoted the Yizong jinjian 醫宗金鑑 (Golden Mirror of the Orthodox Lineage of Medicine, 1742), the official medical compendium commissioned by the Qianlong (r. 1735-96) emperor. ${ }^{77}$

The kaozheng spirit was apparent in this and other imperial compilation projects such as the Siku quanshu 四庫全書 (Complete Library of the Four Treasuries, 1782 , hereafter SKQS).${ }^{78}$ Yet, an official denouncement of all wenbu medicine (and Song learning) by the Qianlong editors or censors did not take place. In the 'abstract' (tiyao 提要) of the skQs edition of Xueshiyian 薛氏醫案 (Medical Case Records of Mr Xue, 1559), the editors took Xu Dachun's criticism on Zhao Xianke into account, but did not expand it to include Xue Ji:

Afterwards, Zhao Xianke wrote Yiguan. Relying on the methods established [by Xue Ji], he cured all diseases with the Pill with Eight Ingredients and the Pill with Six Ingredients. He even treated thirst caused by Cold Damage with the Pill with Six Ingredients. Because 'he glued the tuning pegs when playing the $s e$ [zither]', this caused a lot of malpractices. ${ }^{79}$ Therefore, Xu Dachun composed Yiguan bian. He also aimed his arrows at Mr Xue. However, these [wrong] ideas were originally not [Xue Ji's]. You may not blame Xu Qing [Xunzi] for the mistakes of [his student] Li Si. ${ }^{80}$

according to 'manifestation patterns' (zheng 證). Yet, 'Ke's paradigm shifting innovations, hidden behind claims for reviving ancient medical practice, thereby challenge post-Song medicine far beyond its interpretation of the Treatise', Scheid 2013, p. 342.

77 Shenji chuyan, p. 563. On kaozheng and the Yizong jinjian, see Hanson 2003.

78 On Han learning and the compilation of the SKQS, see Guy 1987.

79 Xueshi yi'an, tiyao, p. 2a-b. By glueing the tuning pegs, the tuning of the instrument cannot be altered anymore. This is a metaphor for stubbornly sticking to one situation, and being unable to change. Cf. HYDCD 6, p. 1374.

8o Xueshi yian, tiyao, p. 2b. Li Si left his master Xunzi to serve the first emperor. However, '[a]fter the death of Emperor Qin Shihuang, Li Si assisted a junior son of the Qin emperor to acquire the throne by illegitimate means and to become the second Qin emperor. In the second year of the second Qin emperor, Li Si himself became a victim of court intrigue and was falsely accused of plotting treason. He was executed by means of the consorted five corporal punishments, which was the cruellest form of execution', Fu 1996, pp. 19-20. Hence, the master (Xunzi/Xue Ji) may not be blamed for the crimes of his student (Li Si/ Zhao Xianke). 
Also in the abstract of Yiguan bian in the Annotated Catalogue of the SKQS, the 'unquestionable efficacy' (wei chang wuxiao 未嘗無效) of Xue Ji's wenbu medicine was highlighted. The editors even complained about the rude language $\mathrm{Xu}$ Dachun used in his attacks on Zhao Xianke. Moreover, they did not see any reason for writing Yiguan bian, as Yiguan was not widely circulating anymore. ${ }^{81}$ Hence, standards were not set to the extremes that Xu Dachun envisioned.

Notwithstanding his fierce criticism of Yiguan, Xu Dachun even absorbed some wenbu influences in his own writings. His famous discussion on 'primary $q i$ ( $y$ uanqi 元氣), a concept which did not feature in the Han medical classics, shows striking parallels with wenbu understandings of the formless fire of the 'gate of life..$^{82} \mathrm{Xu}$ traces the origins of yuanqi back to a place

called 'cinnabar field' in the Taoist classics, called the 'gate of life' in the Nan-ching, and said to be the 'small heart' between the [kidneys, which are located on both] sides of the seventh vertebra in the Nei-ching. ${ }^{83}(. .$. [This place] has no fire and yet it may keep all parts of the body warm; it has no water and yet it may keep the five viscera moist. As long as one last thread remains uncut in there, one thread of vital influences will continue [to maintain a person's life] ${ }^{84}$

Although Xu Dachun does not refer to formless 'minister fire' and 'genuine water' in this context, on a functional level, Xu Dachun's explanation is

81 SKQS zongmu tiyao, pp. 4ob-41a. The SKQs did not only contain texts of Han learning physicians. Although the editors praised efforts by physicians like Xu Dachun, they also included texts of physicians they 'pejoratively labelled as modernists', Elman 2005, p. 235. Yet, as the abstract of Yiguan bian shows, the editors did not entirely follow Xu's ambition to eradicate Xue Ji's wenbu ideas.

82 The term yuanqi 原氣 ('origin qi'), which Xu Dachun equates with yuanqi 元氣, features in NJ 36 (Nanjing jingshi, p. 38). However, he does not consider the NJ to be a classic Yixue yuanliu lun, p. 210. Xu discusses yuanqi 元氣 in the first essay of Yixue yuanliu lun, pp. 163-4; cf. trans. Unschuld 1998, pp. 56-8. He explained other important Song-Ming medical concepts in new ways. In his comments on $\mathrm{NJ} 36$, Xu relates the 'gate of life' to both the eyes as in the Huangdi neijing and the 'thoroughfare vessel' (chongmai 衝脈), Nanjing jingshi, p. 38. He linked 'minister fire' to the pericardium, and not to the gate of life, see Yixue yuanliu lun, pp. 167-8. The distinction between illnesses caused by depletion of the Pre-Heavenly and Post-Heavenly, which was introduced by wenbu physicians, can also be found in Xu's texts, cf. Yixue yuanliu lun, p. 195.

83 Yixue yuanliu lun, p. 163; cf. trans. Unschuld 1998, p. 57.

84 Ibid. For examples of influences of Sun Yikui and Zhang Jiebin on Xu Dachun's theory of yuanqi, see Yang Yungao 1990, p. 7 . 
similar to that of Zhao Xianke. Like wenbu physicians, Xu also paraphrasessw 33: 'If yuanqi is sufficient, external evil cannot cause damage'. ${ }^{55}$ Although he considers expensive replenishing drugs to be unefficacious, Xu often relates to the innate self-healing capacities of yuanqi. ${ }^{86}$

How can this (re)interpretation of the efficacy of yuanqi be understood in the context of the Ming to Qing transition? The late Ming physician Zhao Xianke deemed replenishing necessary to strengthen the bodies of his rich Jiangnan patients, weakened by indulgences in sexual and other pleasures. ${ }^{87}$ The health of a dynasty was, according to Xu Dachun, reflected in the constitution of the people. Xu lived during the high Qing reigns of Kangxi, Yongzheng, and Qianlong. He believed that the 'heavenly mandate' (tianming 天命) was firmly reinstated under Manchu rule:

The era of our current dynasty is a time of extreme prosperity. Sage after Sage follow each other. A strong central authority exists. The morality of the imperial court is upright and deserves respect, and favour flows everywhere. This is clear evidence that the upper echelons are full of yang. Also, one wears red tassels to decorate one's cap, and in their mouths [people] smoke tobacco [sic]. Of all the five phases, only fire prospers. Hence, all illnesses [people develop] are accompanied by pathoconditions resulting from the ascent of exuberant yang. ${ }^{88}$

Hence, attacking and expelling drugs posed no dangers during the high Qing, and had to be used in case of external and internal threats. Yet, as Paul Unschuld suggests, the very metaphor of dispatching soldiers to contain 'rebellions at the

85 Nanjing jingshi, p. 14. See also Yixue yuanliu lun: '[Superior Practitioners] see to it that the original influences are complete and remain in control, so that [the original influences] themselves may keep the evil [influences] outside', p. 164; cf. trans. Unschuld 1998, p. 58.

86 See the discussion on Xu Dachun's ideas on the 'natural tendency of self-healing' (vix medicatrix naturae) in Unschuld 1998, pp. 6-8.

87 Although Zhao Xianke considered aggressive, dispersive formulas to be of some use for the 'robust people of the countryside', they would have devastating effects when treating the decadent, rich upper class, 'endowed with poor health, and brought up in delicate and fragile ways', Yiguan, j. 6, pp. 16b-17a. See also Marta Hanson's discussion on Li Zhongzi's ideas on regionalism: 'Commercial transformation of Chinese society between the time of Xue Ji in the 155 os and Li Zhongzi in the 1620 s, increased the chasm between the rich and poor to such an extent that economic status became a newly resonant marker of even corporeal difference.' (Hanson 2006, p. 164).

88 Yixue yuanliu lun, p. 196; cf. trans. Unschuld 1998, p. 240. For a history of tobacco in China, including its medical uses, see Benedict 2011. 
frontiers' might have been too sensitive for the Qing rulers, and might explain why these passages were censored in the SKQS edition of Xu Dachun's Yixue yuanliu lun. Also, passages critical of contemporary physicians who promoted replenishing formulas were omitted. ${ }^{89}$ Qing officials apparently did not support Xu's crusade against the Jiangnan craze for expensive replenishing drugs, and ginseng in particular. There might be some economic considerations as well. Ginseng was a precious commodity that the Manchu historically traded with the Han Chinese. The monopoly on collection, 'closely tied to the banner organization and the imperial estates', and taxes on the trade of ginseng provided huge revenues for the Qing government. ${ }^{90}$

\section{Conclusion}

Efficacy and safety of medical treatment are a common thread in Zhao Xianke's and Xu Dachun's discourses. Both physicians put prevalent styles of medicine into question, and provided alternatives. They both referred to a loss of tradition, and pleaded for the return to medicine conforming with the classical formulas of Zhang Ji.

In Zhao Xianke's opinion, cooling down in all symptomatic manifestations of heat posed great dangers. Zhu Zhenheng had been correct to point to yin deficiency as the origin of many disorders. However, by failing to recognise the root of yin as the formless fire of the 'gate of life', Zhu and his followers jeopardised correct medical practice. A conservative use of formulas such as Zhang Ji's Pill with Eight Ingredients, which embodied cosmological principles, was the remedy, according to Zhao Xianke. Xu Dachun highlighted that Zhang Ji never elaborated on vague terms such as yin and yang depletion. Instead, he discussed well-defined disorders and manifestations, which could be paired with specific formulas. His critic Xu Dachun considered Zhao Xianke's cosmological explanations, justifying the use of only a handful of formulas, as 'all kinds of nonsense by which he cheated people' (zhongzhong qi ren hushuo 種種欺人胡說). ${ }^{91}$ Although Zhao praised classical formulas, Xu emphasised that he did not understand the basics of Zhang Ji's medicine.

However, things may not be as black and white as they appear. Styles of medicine which scholars today associate with Song learning came in different shades. With their strong emphasis on 'unity between the Three Teachings',

\footnotetext{
89 Unschuld 1998, pp. 28-30. But, contrast with Yixue yuanliu lun, tiyao, p. 1b in skQs.

$90 \quad$ Torbert 1977, pp. 89-92; see also Jiang Zhushan 2007, p. 126.

91 See, for instance, Yiguan bian, p. 147.
} 
wenbu elaborations on the 'supreme ultimate' differed significantly from those of Zhu Zhenheng in the Yuan dynasty (1271-1368). In their search for the roots, these late Ming doctors often challenged orthodox understandings. Therefore, I argue that the role of wenbu physicians in the narrative of epistemic change in the transition from Ming to Qing medicine might have been more pivotal than is generally assumed. Zooming in on individual wenbu texts reveals vibrant discussions on forms and functions in the body which, in turn, informed contemporary and later Cold Damage and Warm disease medicine. Xu Dachun's own theory of yuanqi, for instance, is obviously influenced by wenbu ideas.

Although Zhao Xianke ardently promoted the Pills with Six and Eight Ingredients as effective formulas for treating a wide variety of illnesses, the medicine in Yiguan is far more nuanced and complex than Xu Dachun portrayed. Xu's Yiguan bian should also be read in the political context of the Ming to Qing transition. In his battle against the fad of replenishing, aiming at Yiguan and its populariser, Lü Liuliang, appeared to be a safe bet, as Lü's anti-Manchu writings inspired a failed conspiracy against the Yongzheng emperor. In the aftermath of this incident, Lü's edition of Yiguan ended up as a banned text. In contrast to Xu Dachun, however, the Qianlong editors of the SKQS did not regard the very association of Zhao Xianke's text with Lü Liuliang as a problem. The suggestion that a style of medicine was popularised by this prominent anti-Manchu scholar was irrelevant. The Han learning they embraced had also reached its full maturity within Ming loyalist groups. As they supposed that the text was not circulating anymore, the SKQS editors regarded it as unnecessary to bring back its memory. Moreover, they judged Xu Dachun's own stance as being too radical. The editors saw no reasons for excluding other wenbu texts from the SKQS, and even praised Xue Ji, the father of wenbu medicine, for his effective methods. Moreover, some passages of Xu's Yixue yuanliu lun that might be interpreted as critical of the Qing were censored in the SKQS edition of the text.

Despite Xu Dachun's efforts for safer treatments, 'warming and replenishing' medicine remained popular. And despite the skQs editors' assumptions, Yiguan kept on circulating. Today, Zhao Xianke's text is widely available in various modern editions. Although Zhao's ideas on the 'gate of life' as ruler of the body never became mainstream, he is still remembered as an important wenbu physician. The Pill with Six and the Pill with Eight Ingredients remain among the most popular formulas of Traditional Chinese Medicine (тсм). While some contemporary practitioners are inspired by Han learning or Song learning approaches to Chinese medicine, in general a whole different set of epistemic values prevails. Efficacy and safety of therapies are now tested in the 
lab and through clinical trials. Nonetheless, the outcome of medical treatment is never fully guaranteed. Xu Dachun's worries about the nature and efficacy of medicine still concern us today. How do we assess the quality of medical treatment? And what makes a good doctor?

\section{Acknowledgments}

I wish to thank Lena Springer for her encouragement and editorial work. I am grateful to Volker Scheid and Yi-Li Wu for their comments and suggestions on earlier versions of this article. The two anonymous reviewers have helped me to improve my text significantly. I also wish to thank Isabella Furth for helping me with the map and Mona Schrempf and Marta Hanson for guiding me towards the final version. This research is part of the 'Beyond Tradition' project, funded by the Wellcome Trust. All translations from the Chinese into English are my own unless otherwise noted.

\section{Bibliography}

\section{Primary Sources}

Cangsheng siming 蒼生司命 (Managing Destiny for the Common People, 1515) by Yu Tuan 虞摶 (1438-1517), punctuation and annotation by Wang Daorui 王道瑞 and Shen Haozhen 申好真, Beijing: Zhongguo zhongyiyao chubanshe, 2004.

Fengshi Jinnang milu zazheng daxiao hecan 馮氏錦囊秘錄雜症大小合參 $(\mathrm{Mr}$ Feng's

Secret Records in a Brocade Bag, Combined Inspection of Various Manifestations: Major and Minor, 1694) by Feng Zhaozhang 馮兆張 (17th-18th cent.), in Feng Zhaozhang yixue quanshu 冯兆张医学全书 (Complete Medical Writings of Feng Zhaozhang), edited by Tian Sisheng 田思胜 et al., Beijing: Zhongguo zhongyiyao chubanshe, 1999, 25-582.

Huixi yian 洄溪醫案 (Medical Case Records of Huixi, 1855) attributed to Xu Dachun 徐 大椿 (1693-1771), in Xu Dachun yishu quanji 徐大椿醫書全集 (Complete Collection of Xu Dachun's Medical Writings), edited by Hu Suhua 呼素華, Beijing: Renmin weisheng chubanshe, 1988, 565-607.

Jingyue quanshu 景岳全書 (Complete Writings of Jingyue, 1636) by Zhang Jiebin 張介賓 (1563-1640), in SKQQs.

Kangxi Yinxian zhi 康熙鄞縣誌 (Local History of Yin County of the Kangxi Era, 1686), compiled by Wang Yuanze 汪源澤 and Wen Xingdao 聞性道 (Qing), in Zhongguo difangzhi jicheng 中国地方志集成 (Collection of Chinese Local Histories), Zhejiang 
Fuxian zhi ji 浙江府县志辑 (Collected Local Histories of Counties and Prefectures in Zhejiang), vol. 18, Shanghai: Shanghai shudian chubanshe, 1993.

Leijing 類經 (Classic in Categories, 1622) by Zhang Jiebin 張介賓 (1563-1640), Beijing: Xueyuan chubanshe, 2005.

Leijing fuyi 類經附翼 (Supplement to the Classic in Categories, 1624) by Zhang Jiebin 張 介賓 (1563-1640), in SKQS.

Leijing tuyi 類經圖翼 (Supplement with Illustrations to the Classic in Categories, 1624) by Zhang Jiebin 張介賓 (1563-1640), in SKQS.

Mengzi 孟子 (Master Meng), Shanghai: Shanghai guji chubanshe, 2003.

Nanjing jingshi 難經經釋 (Explanation of the Classic of Difficult Issues [Conform to the Theory in the Inner] Classic, 1727) by Xu Dachun 徐大椿 (1693-1771), in Xu Dachun yishu quanji 徐大椿醫書全集 (Complete Collection of Xu Dachun's Medical Writings), edited by Hu Suhua 呼素華 et al., Beijing: Renmin weisheng chubanshe, 1988, 1-68. Nanleiwen'an 南雷文案 (Literary Cases of Nanlei, 1680) by Huang Zongxi 黃宗羲 (16101695), in Sibu congkan chubian 四部叢刊初編 (Collectanea of the Four Branches: First Series), Shanghai: Shangwu yinshuguan, 1929 [reprint].

Neijing zhiyao 內經知要 (Knowing the Essentials about the Inner Classic, 1642) by Li Zhongzi 李中梓 (1599-1655), in Li Zhongziyixue quanshu 李中梓医学全书 (Collected Medical Writings of Li Zhongzi), edited by Bao Laifa 包来发 et al., Beijing: Zhongguo yiyao chubanshe, 1999, 2-64.

Shanbu yisheng weilun 刪補頣生微論 (Subtle Essays on Nourishing Life, Revised and Supplemented, 1642), by Li Zhongzi 李中梓 (1599-1655), in Li Zhongzi yixue quanshu 李中梓医学全书 (Collected Medical Writings of Li Zhongzi), edited by Bao Laifa 包来发 et al., Beijing: Zhongguo yiyao chubanshe, 1999, 639-754.

Shanghan leifang 傷寒類方 (Classified Formulas of Cold Damage, 1757), by Xu Dachun 徐大椿 (1693-1771), in Xu Dachunyishu quanji 徐大椿醫書全集 (Complete Collection of Xu Dachun's Medical Writings), edited by Hu Suhua 呼素華, Beijing: Renmin weisheng chubanshe, 1988, 227-97.

Shenji chuyan 慎疾媰言 (Humble Opinions on the Careful Treatment of Illnesses, 1767) by Xu Dachun 徐大椿 (1693-1771), in Xu Dachun yishu quanji 徐大椿醫書全集 (Complete Collection of Xu Dachun's Medical Writings), edited by Hu Suhua 呼素華, Beijing: Renmin weisheng chubanshe, 1988, 545-63.

Shennong bencao jing baizhong lu 神農本草經百種錄 (Record of One Hundred Kinds from the Divine Farmer's Classic on Materia Medica, 1736) by Xu Dachun 徐大椿 (1693-1771), in Xu Dachun yishu quanji 徐大椿醫書全集 (Complete Collection of Xu Dachun's Medical Writings), edited by Hu Suhua 呼素華 et al., Beijing: Renmin weisheng chubanshe, 1988, 69-104.

SKQS: Wenyuange Siku Quanshu Dianzi ban 文淵閣四庫全書電子版 (Electronic version of the Wenyuange edition of the Complete Text Collections of the Four Treasuries, 1782), 
edited by Yu Zhiming 余志明, Hong Kong: Dizhi chuban youxian gongsi / Shanghai: Shanghai renmin chubanshe, 2005 .

SKQS Zongmu tiyao: Siku quanshu zongmu tiyao 四庫全書總目提要 (Annotated

Catalogue of the Complete Text Collection of the Four Treasuries), 2 vols, Beijing: Zhonghua zhuju, 1965 .

Sunzi [Bingfa] 孫子 [兵法] ([Military Strategy] of Master Sun), in SKQS.

sw: Huangdi neijing suwen 黃帝內經素問 (Inner Classic of the Yellow Emperor: Basic Questions), commentary by Wang Bing 王冰 (8th cent.), arranged by Lin Yi 林億 (Song) et al., in SKQS.

Xueshi yian, tiyao 薛氏醫案, 提要 (Medical Case Records of Mr Xue, abstract, 1559) by Xue Ji 薛己 (1487-1559), in skQs.

Yiguan 醫貫 (One Principle through Medicine, 1617?) by Zhao Xianke 趙獻可 (16th-17th cent.), with commentary by Lü Liuliang 呂留良 (1629-83), reprint of Tiangai Lou 天蓋樓 edition (Kangxi, 1622-1722), in Siku jinhuishu congkan 四庫禁謏書叢刊 (Collectanea of Books Banned and Destroyed during the Four Treasuries Compilation), edited by Siku jinhuishu congkan weiyuanhui 四庫禁搬書叢刊委員會, Beijing: Beijing chubanshe, 1999 .

Yiguan bian 醫貫矿 (Critique on Yiguan, 1741) by Xu Dachun 徐大椿 (1693-1771), in Xu Dachun yishu quanji 徐大椿醫書全集 (Complete Collection of Xu Dachun's Medical Writings), edited by Hu Suhua 呼素華 et al., Beijing: Renmin weisheng chubanshe, $1988,105-56$.

Yixue yuanliu lun 醫學源流論 (Essays on the Origins of Medicine, 1757), by Xu Dachun 徐大椿 (1693-1771), in Xu Dachun yishu quanji 徐大椿醫書全集 (Complete Collection of Xu Dachun's Medical Writings), edited by Hu Suhua 呼素華 et al., Beijing: Renmin weisheng chubanshe, 1988, 158-225.

Yizhi xuyu 醫旨緒餘 (Additional Instructions on Medicine, 1573) by Sun Yikui 孫一奎 (c. 1522-1619), in SKQS.

Yizong jinjian 醫宗金鑑 (Golden Mirror of the Orthodox Lineage of Medicine, 1742), compiled by Wu Qian 吳謙 (Qing), in SKQs.

\section{Secondary Sources}

Benedict, C. 2011, Golden Silk Smoke: A History of Tobacco in China, 1550-2010, Berkeley and Los Angeles: University of California Press.

Chang Chia-feng 張嘉鳳 1998, 'Shenghua zhi yuan yu liming zhi men: Jin, Yuan, Ming yixue zhong de “mingmen” shitan' 生化之源與立命之門一一金元明醫學中的「命 門」試探 ('The Gate of Life: The Conceptions of Ming-men in Traditional Chinese Medicine in the Chin, Yuan, and Ming Periods'), Xinshixue, 9 (3): 1-47.

Chen Yongping 陈永萍 1995, 'Yiguan banben kaolüe' 《医贯》版本考略 ('Survey of Editions of Yiguan'), Zhongyi wenxian zazhi, 1995 (4):3-5. 
De Bary, W. T. 2000 (2nd), 'Lü Liuliang's Radical Orthodoxy', in W. T. de Bary and R. Lufrano; with the collaboration of W.-T. Chang et al., Sources of Chinese Tradition, vol. 2, New York: Columbia University Press, 18-19.

Deng Zhongjia 邓中甲 (ed.), Fangjixue 方剂学 (Formulas), Beijing: Zhongguo zhongyiyao chubanshe.

Despeux, C. 2001, 'The System of the Five Circulatory Phases and the Six Seasonal Influences (wuyun liuqi): A Source of Innovation in Medicine under the Song (960-1279)', in E. Hsu (ed.), Innovation in Chinese Medicine, Cambridge: Cambridge University Press, 121-65.

De Vries, L. 2012, 'The Gate of Life: Before Heaven and Curative Medicine in Zhao Xianke's Yiguan', PhD dissertation, Universiteit Gent.

De Vries, L. 2014, 'The Authentic Person as Ideal for the Late Ming Dynasty Physician: Daoist Inner Alchemy in Zhang Jiebin's Commentary on the Huangdi neijing', Synthesis Philosophica, 29 (1): 63-82.

Elman, B. A. 1984, From Philosophy to Philology: Intellectual and Social Aspects of Change in Late Imperial China, Cambridge, Mass.: Harvard University Press.

Elman, B. A. 2005, On Their Own Terms: Science in China, 1550-19oo, Cambridge, Mass.: Harvard University Press.

Engelfriet, P. M. 2000, 'Linked Faiths, Divergent Paths? Some Remarks on Taoism and Medicine in Late Ming and Early Qing China', in J. De Meyer and P. M. Engelfriet (eds), Linked Faiths: Essays on Chinese Religions and Traditional Culture in Honour of Kristofer Schipper, Leiden, Boston, and Köln: Brill, 248-68.

Fisher, T. S. 1974, 'Lü Liu-liang (1629-83) and the Tseng Ching Case (1728-33)', PhD dissertation, Princeton University.

Fisher, T. S. 1984, 'Loyalist Alternatives in the Early Qing', Harvard Journal of Asiatic Studies, 44 (1): 83-122.

Fu, Z. 1996, China's Legalists: The Earliest Totalitarians and Their Art of Ruling, Armonk and London: M.E. Sharpe.

Furth, C. 2006, 'The Physician as Philosopher of the Way: Zhu Zhenheng (1282-1358)', Harvard Journal of Asiatic Studies, 66 (2): 423-59.

Goodrich, L. C. 1943, 'Lü Liu-liang', in A. W. Hummel (ed.), Eminent Chinese of the Ch`ing, vol. 1, Washington: Government Printing Office, 551-2.

Guo Junshuang 郭君双 2005, 'Zhengli shuoming' 整理说明 ('Explanations of the Arranger'), Yiguan 医贯 (Medicine Pervaded [by One]), Beijing: Renmin weisheng chubanshe, 7-8.

Guy, R. K. 1987, The Emperor's Four Treasuries: Scholars and the State in the Late Ch'ienlung Era, Cambridge, Mass.: Council on East Asian Studies, Harvard University.

Hanson, M. 2003, 'The Golden Mirror in the Imperial Court of the Qianlong Emperor, 1739-1743, Early Science and Medicine, 8 (2): 111-47. 
Hanson, M. 2006, 'Northern Purgatives, Southern Restoratives: Ming Medical Regionalism', Asian Medicine: Tradition and Modernity, 2 (2): 115-70.

Hanson, M. 2011, Speaking of Epidemics in Chinese Medicine:Disease and the Geographic Imagination in Late Imperial China, Milton Park: Routledge.

Hucker, Ch. 1985, A Dictionary of Official Titles in Imperial China, Stanford: Stanford University Press.

HYDCD: Hanyu dacidian bianji weiyuanhui 汉语大辞典编辑委员会 and Hanyu dacidian bianzuanchu 汉语大辞典编纂处 (eds) 1986-94, Hanyu dacidian 汉语大 词典 (Great Dictionary of the Chinese Language), 12 vols, Shanghai Shanghai cishu chubanshe.

Jiang Zhushan 蒋竹山 2007, 'Fei shen bu zhi, fu bi wan quan: Qing-dai Jiangnan de renshen yaoyong yu buyao wenhua chutan' 非参不治, 服必万全——清代江南的人 参药用与补药文化初探 ('No Treatment Without Ginseng, Its Intake Will Result in Complete Recovery: Preliminary Research on the Medical Use of Ginseng and the Culture of Replenishing Drugs in Jiangnan during the Qing Period'), Zhongguo shehui lishi pinglun, 2007 (8):114-27.

Leung, A. K.-C. 2003, 'Medical Learning from the Song to the Ming', in P. J. Smith and R. von Glahn (eds), The Song-Yuan-Ming Transition in Chinese History, Cambridge, Mass.: Harvard University Asia Center, 374-98.

Ma Yandong 马燕冬 and Sun Zhenghe 孙正和 1997, 'Shixi Xu Dachun de linchuang yixue guifanhua sixiang’ 试析徐大椿的临床医学规范化思想 ('A Tentative Analysis of Xu Dachun's Ideas on the Standardisation of Clinical Medicine'), Beijing zhongyiyao daxue xuebao, 20 (1): 17-19.

Robinet, I. 1990, 'The Place and Meaning of the Notion of Taiji in Taoist sources Prior to the Ming Dynasty', History of Religions, 24 (4): 373-411.

Scheid, V. 2013, 'Transmitting Chinese Medicine: Changing Perceptions of Body, Pathology, and Treatment in Late Imperial China', Asian Medicine: Tradition and Modernity, 8 (2): 299-36o.

Scheid, V. 2014, 'Convergent Lines of Descent: Symptoms, Patterns, Constellations, and the Emergent Interface of Systems Biology and Chinese Medicine', East Asian Science, Technology and Society, 8 (1): 107-39.

Spence, J. 2001, Treason by the Book, New York: Penguin Books.

Struve, L. 1998, The Ming-Qing Conflict, 1619-1683: A Historiography and Source Guide, Ann Arbor: Association for Asian Studies.

Torbert, P. 1977, The Ch'ing Imperial Household Department: A Study of Its Organization and Principal Functions, 1662-1796, Cambridge, Mass.: Harvard University Press.

Unschuld, P. U. (trans. and ann.) 1998, Forgotten Traditions of Ancient Chinese Medicine: A Chinese View from the Eighteenth Century: The I-hsüeh Yüan Liu Lun of 1757 by Hsü Ta-ch'un, translation and annotation, Brookline: Paradigm Publications. 
Wiseman N. and F. Ye 1998, A Practical Dictionary of Chinese Medicine, Brookline: Paradigm Publications.

Wu, Y. 2010, Reproducing Women: Medicine, Metaphor, and Childbirth in Late Imperial China, Berkeley, Los Angeles, and London: University of California Press.

Wu Yunbo 吴云波 1988, 'Xu Dachun Yiguan bian xueshu jiazhi guankui' 徐大椿 《医贯 砭》学术价值管窥 ('On the Scholarly Value of Xu Dachun's Yiguan bian'), Nanjing zhongyixuebao, 1988 (2): 51-3.

Yang Yungao 杨运高 1990, 'Lun Xu Dachun de yuanqi xueshuo' 论徐大椿的元气学说 ('On Xu Dachun's Theory on Primary Qi'), Shaanxi zhongyi xueyuan xuebao, 13 (4): 7-9.

Zhang Wenping 张文平 and Qin Yulong 秦玉龙 2013, 'Xu Dachun shenyong wenbu sixiang qianxi” 徐大椿慎用温补浅析 ('An Analysis of Xu Dachun's Caution against the Use of Warming and Replenishing'), Jiangxi zhongyi xueyuan xuebao, 25 (3): 3-6.

Zhang Xueqian 張學謙 2012, 'Yuan-Ming ruyi sixiang yu shiqian de shehuishi: Yi Zhu Zhenheng ji “Danxi xuepai” wei zhongxin' 元明儒醫思想與實踐的社會史一一以朱 震亨及「丹溪學派」為中心 ('A Social History of Confucian Medical Thought and Practice during the Yuan and the Ming: With a Focus on Zhu Zhenheng and the "Danxi Scholarly Current"'), PhD Dissertation, Chinese University of Hong Kong. 